\title{
Rising the Persian Gulf Black-Lip Pearl Oyster to the Species Level: Fragmented Habitat and Chaotic Genetic Patchiness in Pinctada persica
}

\author{
Mohammad Sharif Ranjbar ${ }^{1}$ - Hossein Zolgharnien ${ }^{2}$ Vahid Yavari ${ }^{3}$. \\ Bita Archangi ${ }^{2} \cdot$ Mohammad Ali Salari $^{2}$. Sophie Arnaud-Haond ${ }^{4}$. \\ Regina L. Cunha ${ }^{5}$
}

Received: 21 January 2015/ Accepted: 31 October 2015/Published online: 9 November 2015

(c) Springer Science+Business Media New York 2015

\begin{abstract}
Marine organisms with long pelagic larval stages are expected to exhibit low genetic differentiation due to their potential to disperse over large distances. Growing body of evidence, however, suggests that marine populations can differentiate over small spatial scales. Here we focused on black-lip pearl oysters from the Persian Gulf that are thought to belong to the Pinctada margaritifera complex given their morphological affinities. This species complex includes seven lineages that show a wide distribution ranging from the Persian Gulf (Pinctada margaritifera persica) and Indian Ocean (P. m. zanzibarensis) to the French Polynesia (P. m. cumingii) and Hawai'i (P. m. galtsoffi). Despite the long pelagic larval phase of $P . \mathrm{m}$.
\end{abstract}

Sophie Arnaud-Haond and Regina L. Cunha have contributed equally to this article.

Electronic supplementary material The online version of this article (doi:10.1007/s11692-015-9356-1) contains supplementary material, which is available to authorized users.

Regina L. Cunha

rcunha@ualg.pt

1 Department of Marine Biology, Faculty of Science, Hormozgan University, Bandar Abbas, Iran

2 Department of Marine Biology, Faculty of Marine Science, Khoramshahr University of Marine Science and Technology, Khorramshahr, Iran

3 Department of Fishery, Faculty of Marine Resources, Khoramshahr University of Marine Science and Technology, Khorramshahr, Iran

4 IFREMER - UMR MARBEC (Marine Biodiversity, Exploitation and Conservation), Bd Jean Monnet, BP 171, 34203 Sète Cedex, France

5 Centre of Marine Sciences (CCMAR), University of Algarve, Campus de Gambelas, 8005-139 Faro, Portugal persica, this lineage is absent from continental locations and can only be found on a few islands of the Persian Gulf. Mitochondrial COI-based analyses indicated that $P$. m. persica belongs to a clearly divergent ESU and groups with specimens from Mauritius (P. m. zanzibarensis). Microsatellite data, used here to assess the spatial scale of realized dispersal of Persian Gulf black-lip pearl oysters, revealed significant genetic structure among islands distant of only a few dozen kilometres. The scantiness of suitable habitats most likely restricted the distribution of this lineage originating the observed chaotic genetic patchiness. The hatchery-based enhancement performed in one of the sampled islands may also have affected population genetic structure. The long-term accumulation of genetic differences likely resulted from the allopatric divergence between $P$. m. persica and the neighbouring Indian Ocean black-lip pearl oysters.

Keywords Black-lip pearl oysters - Pinctada persica . Species delimitation - Persian Gulf · Fragmented habitat

\section{Introduction}

It has been widely accepted that marine species with extended planktonic larval phases exhibit broader geographic ranges and lower extinction/speciation rates (Marshall Dustin and Morgan Steven 2011). Recent studies showed, however, the existence of intraspecific differentiation and cryptic speciation (e.g. the Indo-Pacific giant clams Huelsken et al. 2013) or diversification at exceptionally small spatial scales (e.g. the marine red alga genus Portieria, Payo et al. 2013), in species showing this type of larval development. Considering the widespread shallowwater habitat deterioration due to increasing levels of pollution and anthropogenic disturbance, the ability to 
disperse among patchy habitats assumes a crucial role in population dynamics and species evolution (Nanninga and Berumen 2014).

The black-lip pearl oysters described as Pinctada margaritifera exhibit a wide distribution range, spanning from the Hawai'i (P. m. galtsoffi) and French Polynesia (P. m. cumingii) to the Indian Ocean (southern Africa, $P . m$. zanzibarensis) and Persian Gulf ( $P$. m. persica). As in many bivalve genera where morphological characters proved highly plastic (Hollander 2008), there is a considerable uncertainty as to the number of evolutionary significant units (ESUs) hidden within the $P$. margaritifera complex, initially described on the basis of morphological criteria only (Jameson 1901). For instance, a molecular phylogeny of the genus (Cunha et al. 2011) showed that black-lip pearl oysters from Mauritius previously classified as $P$. m. zanzibarensis, did not group with the remaining conspecific $P$. margaritifera from the French Polynesia.

Pinctada pearl oysters are broadcast spawners, releasing gametes in the water column, with a pelagic larval life ranging from 16 to 30 days depending on the species (Gervis and Sims 1992). Observations in captivity of P. m. persica showed that the larval period could extend up to 35 days (pers. comm. Hossein Rameshi; Persian Gulf Molluscs Research Centre, Bandar Lengeh, Iran). Unlike $P$. margaritifera that occurs from the Gulf of California to the Eastern Mediterranean Sea (Sims 1992), the black-lip pearl oysters from the Persian Gulf show an unusual distribution restricted to a few islands located in the Gulf (Larak, Shidvar, Hendurabi, Khark, Hengam and south of Qeshm Island; see Fig. 1 for further details). No records of their presence along the continental landmasses surrounding the Persian Gulf (Iran, Saudi Arabia, Qatar and United Arab Emirates) have ever been reported (Hasan 1994; Mohammed and Al-Khayat 1994). These large-shelled oysters are typically found on coral reefs and rocky bottoms in strongcurrent, high-turbidity waters, and frequently associated with sponges. Insular black-lip oysters can occur in sympatry with Pinctada radiata, an abundant species throughout the Persian Gulf, both on islands and continental locations.

Here, we focused on the molecular characterization of P. m. persica from the islands of the Persian Gulf using available mitochondrial cytochrome oxidase I (COI) sequence data of the genus Pinctada to establish the phylogenetic position of this lineage within the $P$. margaritifera complex. Species delimitation analyses were used to test whether specimens from the Persian Gulf represent a subspecies of $P$. margaritifera or form an independent lineage. We also dated lineage-splitting events within Pinctada using a Bayesian relaxed molecular-clock approach to estimate the age of $P$. m. persica. Microsatellite loci were used to assess the spatial scale of realized dispersal of black-lip pearl oysters inhabiting different islands of the Persian Gulf.

\section{Methods}

\section{Specimen Collection, DNA Extraction, Amplification and Sequencing}

Black-lip pearl oysters from the islands of the Persian Gulf occur in extremely low numbers and we were only able to collect a total of 51 specimens by scuba diving (more than 150 dives in total) from the following islands located in the Persian Gulf: Larak, closer to the Strait of Hormuz (24 samples), Shidvar (14 samples), Hendurabi (8 samples) and Khark (5 samples) in the northwest (see map from Fig. 1 for further details). All laying beds but Shidvar are expected to result from natural recruitment. Since 2004, regular spat releases have been performed to restore Shidvar sites using hatchery production from spawners in Hendurabi aquaculture facilities: about 2300 specimens were released in 2004 and between 2005 and 2009 about 10,000 every year (Rameshi 2014). Mantle tissue samples were preserved in $96 \%$ ethanol, and total genomic DNA was isolated using the CTAB extraction method from Porebski et al. (1997).

Barcoding analyses were performed with 27 of those specimens (Larak: 14 samples; Hendurabi: 8 samples; Khark: 5 samples). Given the geographic proximity of the islands Hendurabi and Shidvar $(<40 \mathrm{~km}$ apart) and considering that spawners from Hendurabi produced most of the spats of Shidvar, all mtDNA analyses were based on the eight samples from Hendurabi.

The primers from Folmer et al. (1994) were used to amplify a fragment of about 650 base pairs (bp) of the mitochondrial cytochrome oxidase subunit I (COI) gene. PCR amplifications were carried out in $25 \mu \mathrm{l}$ reactions containing $10 \times$ PCR polymerase buffer (Bioneer), $2 \mathrm{mM}$ of $\mathrm{MgCl}_{2}, 0.2 \mathrm{mM}$ of each dNTP, $0.4 \mu \mathrm{M}$ of each primer, and 1 unit of $T a q$ polymerase (Bioneer), and using the following profile: an initial denaturing step at $94{ }^{\circ} \mathrm{C}$ for $4 \mathrm{~min}$; 30 cycles of denaturing at $94{ }^{\circ} \mathrm{C}$ for $45 \mathrm{~s}$, annealing at $45{ }^{\circ} \mathrm{C}$ for $40 \mathrm{~s}$, and extending at $72{ }^{\circ} \mathrm{C}$ for $1 \mathrm{~min}$; a final extending step at $72{ }^{\circ} \mathrm{C}$ for $5 \mathrm{~min}$. Sequencing results from amplicons purified using the Bioneer K3035-1 kit and directly sequenced with the corresponding PCR primers. Sequencing was performed in an automated sequencer (Sanger) following manufacturer's instructions. The obtained different haplotypes were deposited in GenBank under the accession numbers: AB777259-AB777263.

\section{Phylogenetic Reconstruction}

To analyse phylogenetic patterns within Pinctada, all available COI sequences of the genus and three outgroups (Pteria sterna, Pteria hirundo, Pteria loveni) were 


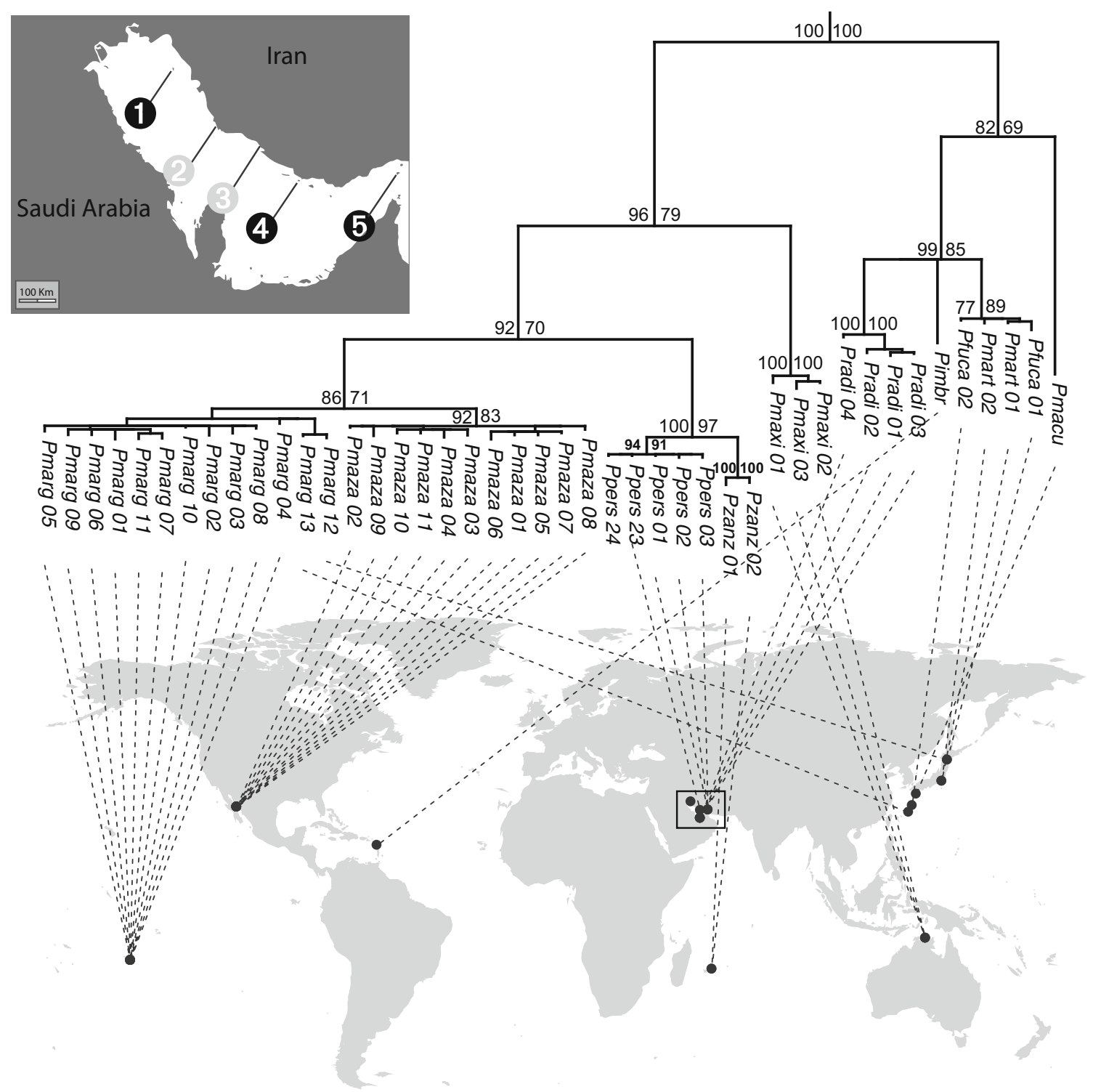

Fig. 1 Phylogenetic relationships of the genus Pinctada based on Bayesian inference analysis of the mitochondrial cytochrome oxidase subunit I (COI) sequence data using the TVM+G evolutionary model. Numbers in the nodes correspond to Bayesian posterior probabilities-BPP (on the left side of the branch) and maximum likelihood bootstrap proportions-BP (on the right side of the branch). Only BP

retrieved from GeneBank (accession numbers in Table 1). DNA sequences (73 in total, 27 from this study) were aligned using MAFFT version 6.0 (Katoh and Toh 2010) using the-auto option that automatically selects the appropriate strategy according to data size, which yielded an alignment with $506 \mathrm{bp}$. No insertions or deletions were observed and amino acid translations were checked using Geneious v.7.1.4 (Drummond et al. 2010). Identical haplotypes from the COI data set were collapsed with DNACOLLAPSER (http://www.birc.au.dk/software/fabox) producing a data set with 47 unique haplotypes, 5 from the Persian Gulf, that were used in all phylogenetic analyses. and BPP values above $50 \%$ are represented. Black circles indicate sample locations. The inset shows the Persian Gulf. Numbers in black circles indicate island locations ( 1 Khark, 4 Hendurabi-Shidvar, 5 Larak). The grey circles represent continental coral reef areas (2 Nakhiloo, 3 Nayband) where only Pinctada radiata can be found. The scale (in $\mathrm{km}$ ) is indicated

The Akaike Information Criterion (AIC) (Akaike 1973) implemented in Modeltest v.3.7 (Posada and Crandall 1998) selected TVM+G the evolutionary model that better fits the data set. Bayesian Inference (BI) and maximum likelihood (ML) analyses were performed using MRBAYES v.3.1.2 (Huelsenbeck and Ronquist 2001) and PhyML v.3.0 (Guindon and Gascuel 2003), respectively. The BI analysis was performed under the $\mathrm{TVM}+\mathrm{G}$ evolutionary model. Since this model is not available in PhymL, the GTR $+\mathrm{G}$ (the second best-fit model) was used in the ML analysis. Inferred model parameters were used in the ML analysis, and the robustness of the inferred trees was evaluated using 
Table 1 List of specimens used in this study, sample locations and GenBank accession numbers

\begin{tabular}{|c|c|c|c|}
\hline Species & Codes & Location & GenBank \\
\hline Pinctada persica & Ppers01 & Larak, Persian Gulf & AB777259 \\
\hline Pinctada persica & Ppers02 & Larak, Persian Gulf & AB777259 \\
\hline Pinctada persica & Ppers03 & Larak, Persian Gulf & AB777259 \\
\hline Pinctada persica & Ppers04 & Larak, Persian Gulf & AB777260 \\
\hline Pinctada persica & Ppers05 & Larak, Persian Gulf & AB777259 \\
\hline Pinctada persica & Ppers06 & Larak, Persian Gulf & AB777259 \\
\hline Pinctada persica & Ppers08 & Larak, Persian Gulf & AB777259 \\
\hline Pinctada persica & Ppers09 & Larak, Persian Gulf & AB777259 \\
\hline Pinctada persica & Ppers10 & Larak, Persian Gulf & AB777259 \\
\hline Pinctada persica & Ppers11 & Larak, Persian Gulf & AB777259 \\
\hline Pinctada persica & Ppers12 & Larak, Persian Gulf & AB777259 \\
\hline Pinctada persica & Ppers13 & Larak, Persian Gulf & AB777259 \\
\hline Pinctada persica & Ppers14 & Larak, Persian Gulf & AB777261 \\
\hline Pinctada persica & Ppers15 & Larak, Persian Gulf & AB777262 \\
\hline Pinctada persica & Ppers16 & Hendurabi, Persian Gulf & AB777259 \\
\hline Pinctada persica & Ppers17 & Hendurabi, Persian Gulf & AB777259 \\
\hline Pinctada persica & Ppers18 & Hendurabi, Persian Gulf & AB777259 \\
\hline Pinctada persica & Ppers19 & Hendurabi, Persian Gulf & AB777259 \\
\hline Pinctada persica & Ppers20 & Hendurabi, Persian Gulf & AB777259 \\
\hline Pinctada persica & Ppers21 & Hendurabi, Persian Gulf & AB777259 \\
\hline Pinctada persica & Ppers22 & Hendurabi, Persian Gulf & AB777259 \\
\hline Pinctada persica & Ppers23 & Hendurabi, Persian Gulf & AB777263 \\
\hline Pinctada persica & Ppers24 & Khark, Persian Gulf & AB777259 \\
\hline Pinctada persica & Ppers25 & Khark, Persian Gulf & AB777259 \\
\hline Pinctada persica & Ppers26 & Khark, Persian Gulf & AB777259 \\
\hline Pinctada persica & Ppers27 & Khark, Persian Gulf & AB777259 \\
\hline Pinctada persica & Ppers28 & Khark, Persian Gulf & AB777259 \\
\hline Pinctada margaritifera cumingii & Pmarg01 & French Polynesia & AF374320 \\
\hline Pinctada margaritifera cumingii & Pmarg02 & French Polynesia & AF374321 \\
\hline Pinctada margaritifera cumingii & Pmarg03 & French Polynesia & AF374322 \\
\hline Pinctada margaritifera cumingii & Pmarg04 & French Polynesia & AF374323 \\
\hline Pinctada margaritifera cumingii & Pmarg05 & French Polynesia & AF374324 \\
\hline Pinctada margaritifera cumingii & Pmarg06 & French Polynesia & AF374325 \\
\hline Pinctada margaritifera cumingii & Pmarg07 & French Polynesia & AF374326 \\
\hline Pinctada margaritifera cumingii & Pmarg08 & French Polynesia & AF374327 \\
\hline Pinctada margaritifera cumingii & Pmarg09 & French Polynesia & AF374328 \\
\hline Pinctada margaritifera cumingii & Pmarg 10 & French Polynesia & AF374329 \\
\hline Pinctada margaritifera cumingii & Pmarg11 & French Polynesia & AF374330 \\
\hline Pinctada margaritifera & Pmarg 12 & Okinawa, Japan & AB259166 \\
\hline Pinctada margaritifera & Pmarg13 & Japan & AB259165 \\
\hline Pinctada zanzibarensis & Pzanz01 & Mauritius & GQ355869 \\
\hline Pinctada zanzibarensis & Pzanz02 & Mauritius & GQ355872 \\
\hline Pinctada margaritifera mazatlanica & Pmaza01 & Gulf ofCalifornia & AF374307 \\
\hline Pinctada margaritifera mazatlanica & Pmaza02 & Gulf of California & AF374308 \\
\hline Pinctada margaritifera mazatlanica & Pmaza03 & Gulf of California & AF374309 \\
\hline Pinctada margaritifera mazatlanica & Pmaza04 & Gulf of California & AF374310 \\
\hline Pinctada margaritifera mazatlanica & Pmaza05 & Gulf of California & AF374311 \\
\hline Pinctada margaritifera mazatlanica & Pmaza06 & Gulf of California & AF374312 \\
\hline Pinctada margaritifera mazatlanica & Pmaza07 & Gulf of California & AF374313 \\
\hline Pinctada margaritifera mazatlanica & Pmaza08 & Gulf of California & AF374314 \\
\hline
\end{tabular}


Table 1 continued

\begin{tabular}{|c|c|c|c|}
\hline Species & Codes & Location & GenBank \\
\hline Pinctada margaritifera mazatlanica & Pmaza09 & Gulf of California & AF374315 \\
\hline Pinctada margaritifera mazatlanica & Pmaza10 & Gulf ofCalifornia & AF374316 \\
\hline Pinctada margaritifera mazatlanica & Pmaza11 & Gulf of California & AF374317 \\
\hline Pinctada margaritifera mazatlanica & Pmaza12 & Gulf of California & AF374318 \\
\hline Pinctada margaritifera mazatlanica & Pmaza13 & Gulf of California & AF374319 \\
\hline Pinctada maxima & Pmaxi01 & Northern Australia & GQ355881 \\
\hline Pinctada maxima & Pmaxi02 & Northern Australia & GQ355880 \\
\hline Pinctada maxima & Pmaxi03 & Northern Australia & GQ355879 \\
\hline Pinctada radiata & Pradi01 & United Arab Emirates & GQ355878 \\
\hline Pinctada radiata & Pradi02 & United Arab Emirates & GQ355877 \\
\hline Pinctada radiata & Pradi03 & United Arab Emirates & GQ355876 \\
\hline Pinctada radiata & Pradi04 & United Arab Emirates & GQ355875 \\
\hline Pinctada imbricata & Pimbr01 & Guadeloupe Island & GQ355883 \\
\hline Pinctada imbricata & Pimbr02 & Guadeloupe Island & GQ355873 \\
\hline Pinctada imbricata & Pimbr03 & Guadeloupe Island & GQ355870 \\
\hline Pinctada fucata & Pfuca01 & Amami, Japan & DQ299941 \\
\hline Pinctada fucata & Pfuca02 & Japan & GQ355871 \\
\hline Pinctada martensii & Pmart01 & Japan; Kanagawa & AB076915 \\
\hline Pinctada martensii & Pmart02 & Japan; Kanagawa & GQ355882 \\
\hline Pinctada maculata & Pmacu & Kagoshima, Japan & AB261166 \\
\hline Pteria hirundo & N/A & N/A & AF120647 \\
\hline Pteria sterna & N/A & N/A & AY223839 \\
\hline Pteria loveni & N/A & N/A & AB076925 \\
\hline
\end{tabular}

nonparametric bootstrap proportions (BP) with 1000 pseudo-replicates. Metropolis-coupled Markov chain Monte Carlo (MCMC) analyses were run for 20,000,000 generations with a sample frequency of 2000. Length of burn-in was determined by visual inspection of traces in TRACER V.1.6 (Drummond and Rambaut 2008), and the first 20,000 generations were discarded. Robustness of the inferred trees was evaluated using Bayesian posterior probabilities (BPP). The data set was analysed in two independent runs and the final tree was obtained from the combination of the accepted trees from each run. Convergence between the two runs was assessed by examining the potential scale reduction factors (PSRF) and effective sample size (ESS).

\section{Species Delimitation Tests}

We used the GMYC (general mixed Yule-coalescent) model (Pons et al. 2006) to evaluate if the specimens of the black-lip pearl oyster from the Persian Gulf could be considered a new species. The GMYC method identifies the transition from coalescent to speciation branching patterns on an ultrametric tree based on a threshold time (T), as implemented in Splits, code written by T. Ezard, T. Fujisawa and T. Barraclough in R v.3.0.2 (R Development
Core Team 2013). All nodes before this threshold time reflect diversification events whereas after reflect coalescent events (Pons et al. 2006).

To identify the number of ESUs using the GMYC method, we used an ultrametric tree obtained with BEAST v.2.1.3 (Bouckaert et al. 2014), a relaxed lognormal clock but without fossil calibrations, and a fixed mean rate of mutations set to one. A constant coalescent prior was used instead of a Yule prior because is thought to be more conservative for species delimitation (Monaghan et al. 2009). The analysis ran for 500,000,000 generations, sampling every 5000 generations. Length of burn-in was determined by visual inspection of traces in TRACER v.1.6. The final tree was produced by TREEANNOTATOR v.1.7.4 (Drummond et al. 2012) using the "maximum clade creditability" option and mean node height, and was calculated based on 99,501 trees (after burn-in of 500 generations). The convergence to the stationary distribution was confirmed by inspection of the MCMC samples and of effective sample sizes (ESS should be $>200$ ) using TRACER v1.6. (Rambaut et al. 2014). Support for nodes was determined using BPP calculated by BEAsT.

We also used the ABGD (Automatic Barcode Gap Discovery, web server available at http://wwwabi.snv.jus sieu.fr/public/abgd/abgdweb) method to further analyse the 
taxonomic status of the Pinctada specimens from the islands of the Persian Gulf. This method is based on the assumption that "barcode gap, which can be observed whenever the divergence among organisms belonging to the same species is smaller than divergence among organisms from different species" (Puillandre et al. 2012a) generates a noncontinuous distribution of pairwise genetic distances, revealing the occurrence of distinct taxa in the set of specimens analysed. First, it computes the theoretical maximal limit of the intraspecific diversity (using a coalescent model) and then identifies a limit between the two modes of the distribution, at intra and inter-specific levels (Puillandre et al. 2012b). ABGD also uses several a priori thresholds to propose partitions of the individuals into species based on the distribution of pairwise genetic distances (Puillandre et al. 2012b). We selected the Kimura two-parameters model (Kimura 1980), the X value (minimum relative barcoding gap width) of 1.2 , and the following prior intraspecific divergences: Pmin $=0.000001$ and $\operatorname{Pmax}=0.1$ to run the barcode gap analysis.

\section{Dating Analyses and Diversification Rates}

We used BEAST v.2.1.3 (Bouckaert et al. 2014) to estimate age splitting events within Pinctada. This methodology uses a relaxed molecular clock Bayesian approach and probabilistic calibration priors instead of point calibrations, allowing the incorporation of fossil uncertainties (Drummond et al. 2006). We used an uncorrelated relaxed, lognormal clock with two calibrations based on the fossil record. We ran the analysis for 500,000,000 generations, sampling every 5000 generations. Length of burn-in was determined by visual inspection of traces in TRACER v.1.6. The final tree was produced by TREeANNOTATOR using the "maximum clade creditability" option and mean node height, and was calculated based on 99,501 trees (after burn-in of 500 generations). The convergence to the stationary distribution was confirmed by inspection of the MCMC samples and of effective sample sizes (ESS should be >200) using TRACER v1.6. Support for nodes was determined using BPP calculated by BEAST.

We used a lognormal prior distribution on the age of the stem lineages of the genus Pinctada with $95 \%$ range from 23 to $5.3 \mathrm{Ma}$ based on the first occurrence of the genus in the paleontological record during the Miocene (Hertlein and Cox 1969). Parameters were: mean in real space, $\mathrm{M}=4.1 ; \mathrm{S}=1.0$; Offset: 5.3. A lognormal prior distribution was also used from the second calibration with $95 \%$ range from 5.33 to $1.8 \mathrm{Ma}$ based on the existence of a fossil of $P$. mazatlanica reported from the Pliocene of Baja California (Moore 1983). Parameters: mean in real space: 0.814 ; standard deviation: 1.0 ; offset: 1.8 .
We examined rates of diversification across the reconstructed BEAST chronogram using the relative cladogenesis statistic implemented in ENDEPI v1.01 (Rambaut et al. 1997) that identifies branches in the tree that have higher rates than expected under a constant-rate birth-death model.

\section{Microsatellite Analyses}

Genomic DNA was isolated from 5 to $10 \mathrm{mg}$ of muscle tissue using the CTAB method (Doyle and Doyle 1987). A total of 51 samples from four islands of the Persian Gulf: Larak (24 samples), Shidvar (14 samples), Hendurabi (8 samples) and Khark (5 samples) were scored for ten polymorphic microsatellite loci developed for the black-lip pearl oyster P. margaritifera (Herbinger et al. 2006). PCR conditions were carried out in $25 \mu \mathrm{l}$ reactions containing $10 \times$ PCR polymerase buffer (Bioneer), $2 \mathrm{mM}$ of $\mathrm{MgCl}_{2}$, $0.2 \mathrm{mM}$ of each dNTP, $0.4 \mu \mathrm{M}$ of each primer, and 1 unit of Taq polymerase (Bioneer), and using the following profile: an initial denaturing step at $94{ }^{\circ} \mathrm{C}$ for $3 \mathrm{~min}$; 30 cycles of denaturing at $94{ }^{\circ} \mathrm{C}$ for $1 \mathrm{~min}$, annealing at $48-52{ }^{\circ} \mathrm{C}$ for $30 \mathrm{~s}$ depending on the primer, and extending at $72{ }^{\circ} \mathrm{C}$ for $1 \mathrm{~min}$; a final extending step at $72{ }^{\circ} \mathrm{C}$ for 5 min. PCR fragments were loaded on acrylamide gels for $2 \mathrm{~h}$ at $150 \mathrm{~V}$, and stained using with silver nitrate (Bassam et al. 1991).

Descriptors of the genetic diversity and structure of samples to estimate allelic richness, unbiased and observed heterozygosity, and departure from Hardy-Weinberg Equilibrium (HWE) $\left(\mathrm{F}_{\mathrm{is}}\right.$ ), as well as linkage disequilibrium (Black and Krafsur 1985) were computed using GeNETIX (Belkhir et al. 1996-2004). To assess the existence of spatial genetic structure among sampled sites, the $\mathrm{F}_{\text {st }}$ estimator $\theta$ was computed (Weir and Cockerham 1984) using Genetix (Belkhir et al. 1996-2004), and clustering analysis was performed using the Bayesian Markov Chain Monte Carlo (MCMC) in Structure v.2.3.4 (Pritchard et al. 2000), with admixture and correlated allele frequencies. For each number of putative differentiated clusters (k comprised between 1 and 4), ten replicates were run with 200.000 steps after an initial burn-in period of 50.000 steps. The stabilization of MCMC was inferred from log-likelihood graphs. Additionally, the $\Delta \mathrm{K}$ method (Evanno et al. 2005) implemented in StructureHarvester (Earl 2012) was used to confirm the best-supported number of differentiated clusters.

Considering the small sample size we had access to, we favored individual based assessment of genetic clustering. To determine genetic structuring and individual assignments based on the autosomal microsatellite data set, we used Discriminant Analysis of Principal Components (DAPC) a multivariate ordination method (Jombart 2008) 
implemented in the ADEGENET package (Jombart 2008) of $\mathrm{R}$ 2.15.3 (R Development Core Team 2013). This method does not assume Hardy-Weinberg equilibrium or linkage disequilibrium and is more appropriate for situations where such assumptions are not met, than conventional approaches such as structure (Pritchard et al. 2000). A userspecified number of principal components is retained to act as predictors, in this case, representing $75 \%$ of the cumulative variance.

\section{Results}

\section{Phylogenetic Analyses}

The 47 partial sequences (after removing identical haplotypes) of the mitochondrial COI gene from all available Pinctada species produced an alignment of 506 nucleotides. Of these, 210 were invariant and 55 were phylogenetic informative. BI $(-\ln \mathrm{L}=4037.99)$ and $\mathrm{ML}$ $(-\ln \mathrm{L}=3985.82)$ analyses arrived at an identical topology (Fig. 1). In both analyses, the specimens from the islands of the Persian Gulf clustered in a well-supported clade. These specimens did not cluster with $P$. radiata (the only species occurring in the same geographical area), and their nearest cluster was formed of specimens assigned to $P$. margaritifera from Mauritius in the Indian Ocean (Fig. 1). P. fucata and P. martensii were retrieved as nonmonophyletic. Overall results are congruent with (Cunha et al. 2011), and show the position $P$. $m$. persica as a distinct but closest neighbour lineage of $P$. m. zanzibarensis (Fig. 1).

Sequence divergence within Pinctada species calculated with Mega v.5.04 (Tamura et al. 2011) using Tajima-Nei evolutionary model (Tajima and Nei 1984) and 500 bootstrap replicates, ranged from 0.00024 to 0.401 . The genetic distance within specimens from the islands of the Persian Gulf was $0.00024 \pm 0.0002$, and between these specimens and its closest sister group ( $P$. margaritifera from Mauritius), was $0.035 \pm 0.009$. The remaining genetic distances are shown in Table S1.

\section{Species Delimitation Tests}

The single-threshold (Pons et al. 2006) test showed that the likelihood of the null model (all specimens belong to a single species) was significantly poorer than the maximum likelihood of the GMYC model (268.86 vs. 278.91; likelihood ratio: $\left.20.11, P=1.6 \times 10^{-4}\right)$. The number of obtained clusters was seven $[95 \%$ confidence interval $(\mathrm{CI})$ 5-8]. The total number of ML entities (number of ESUs within Pinctada) was 13 (95\% CI 10-15). When applying the ABGD method, the distribution of genetic distances was grouped into two modes separated by a "barcode gap" between 0.44 and 0.98 (results not shown). ABGD test (Fig. 2B) clustered sequences into 12 ESUs (nine within Pinctada).

Overall results were congruent among all methods with two exceptions: (1) a specimen from the French Polynesia (MARG105), which GMYC considered a different species (Fig. 2A) and the ABGD including it within the remaining P. margaritifera specimens from this area (Fig. 2B); (2) the clade $P$. margaritifera with both specimens from Japan (Fig. 2) is considered a different species with GYMC (Fig. 2A) whereas ABGD includes it within P. margaritifera from the French Polynesia (Fig. 2B). ESUs identified as species in this study are those that are recognized in GMYC, ABGD and Bayesian analyses. Therefore, only nine ESUs are considered as valid species within Pinctada. Both GMYC and ABGD clearly separated specimens from the islands of the Persian Gulf as a different species.

\section{Lineage Splitting Events Within Pinctada}

The crown group age of the specimens from the islands of the Persian Gulf ( $P$. persica) was estimated at 0.51 [0.06-1.42] myr, and divergence from its sister group $(P$. margaritifera specimens from Mauritius, $P$. zanzibarensis) was estimated at 2.29 [0.73-4.62] myr (Fig. 1). The age of the crown group that includes all $P$. margaritifera specimens except the ones from Mauritius was 2.25 [1.06-3.94] myr. The estimated age for $P$. radiata was 1.02 [0.23-2.38] myr (Fig. 1).

No significant changes in rates were observed in the phylogeny using the rate of cladogenesis statistic so no further investigation was undertaken.

\section{Population Differentiation}

Among the 51 specimens genotyped for the seven polymorphic loci (ten microsatellite loci were scored, among which three were not polymorphic, therefore, all estimates were based on the remaining seven loci), none failed amplification and an average of 3.9-5.1 alleles per loci was observed (Table 2). Unbiased heterozygosity spanning from 0.71 to 0.85 (Table 2 ) revealed a clear tendency to higher richness and heterozygosity with larger sample sizes. Large departures from HWE were detected, with much lower observed $\left(\mathrm{H}_{\mathrm{obs}}\right.$ from 0.34 to 0.61$)$ than unbiased expected heterozygosity (Table 2). That resulted in large and significant $F_{\text {is }}$ values for all loci analysed in one, or more locations (Table S2), particularly significant in those locations where less than ten samples analysed (Hendurabi; Tables 3 and S2). Linkage disequilibrium showed no loci specific pattern; nonetheless, a larger amount $(20 \%, p<0.05)$ of significant disequilibrium than 


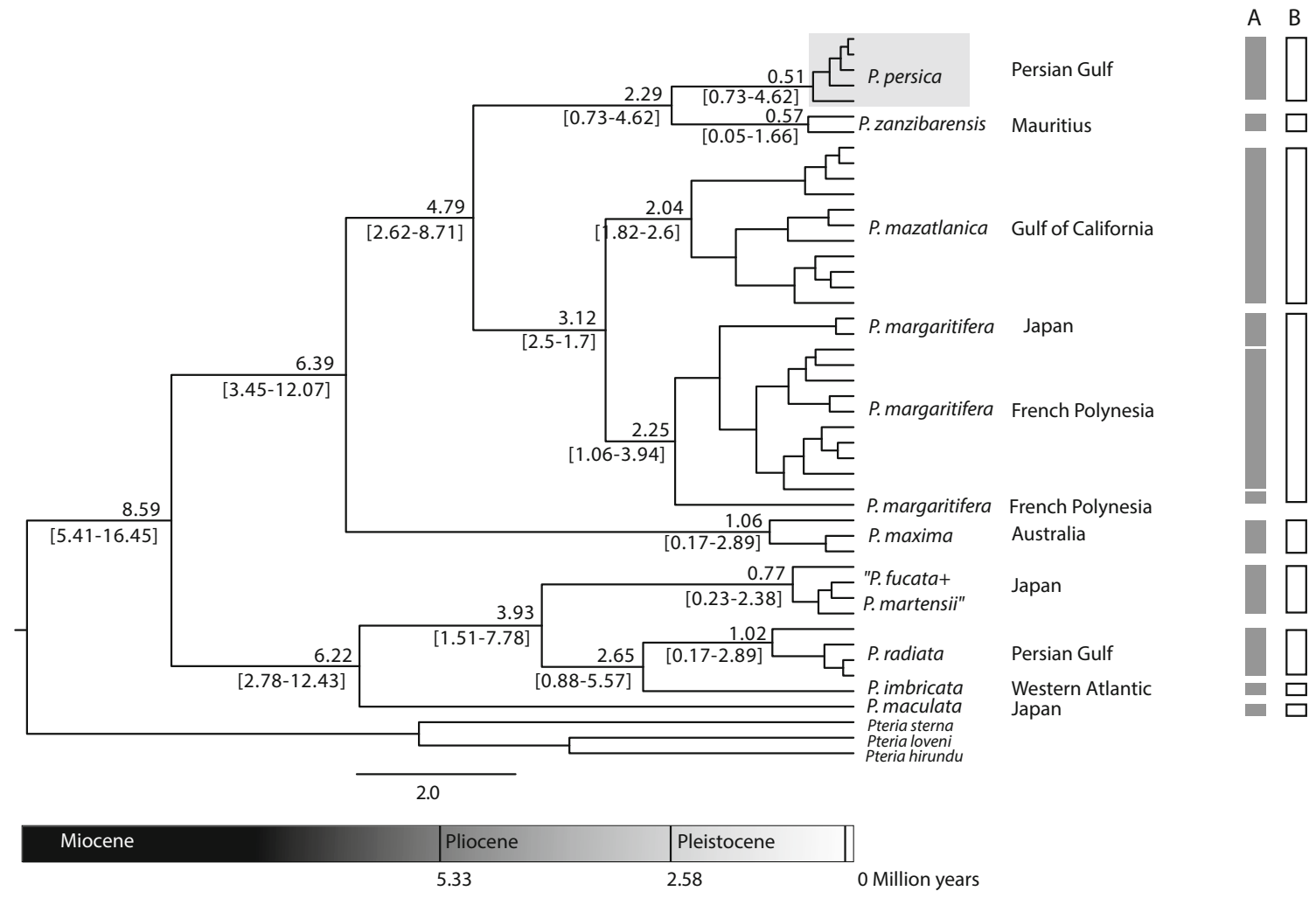

Fig. 2 BEAST maximum clade credibility chronogram. Age estimates in million years and corresponding $95 \%$ highest posterior density intervals (values in square brackets) are depicted. Shaded area represents specimens assigned to $P$. persica. (A) GMYC test based on an ultrametric tree produced using BEAST for the cytochrome oxidase

Table 2 Number of specimens of Pinctada persica analyzed (N) analyzed with microsatellite data, allelic richness standardized for the lowest sample size (A. loci for $\mathrm{N}=5$ ), unbiased $(\mathrm{Hnb})$ and observed $\left(\mathrm{H}_{\mathrm{obs}}\right)$ heterozygosity, and departure from Hardy-Weinberg Equilibrium $\left(\mathrm{F}_{\text {is }}\right)$

\begin{tabular}{lrllll}
\hline Location & $\mathrm{N}$ & A.loci $^{-1}$ & $\mathrm{H}_{\mathrm{nb}}$ & $\mathrm{H}_{\text {obs }}$ & $F_{\text {is }}$ \\
\hline Larak & 24 & 5.09 & $0.85 \pm 0.03$ & $0.61 \pm 0.26$ & $\mathbf{0 . 2 8 1}$ \\
Khark & 5 & 4.14 & $0.71 \pm 0.08$ & $0.49 \pm 0.32$ & 0.343 \\
Shidvar & 14 & 4.74 & $0.82 \pm 0.05$ & $0.47 \pm 0.18$ & $\mathbf{0 . 4 3 6}$ \\
Hendurabi & 8 & 3.89 & $0.73 \pm 0.13$ & $0.34 \pm 0.24$ & 0.552 \\
\hline
\end{tabular}

Values significantly departing from those expected under the null hypothesis of panmixia are indicated in bold $(p<0.01)$

expected at random (alpha $=5 \%$ ) was detected for both localities with more than ten samples analyzed (Larak and Shidvar).

Genetic differentiation estimated through pairwise $F_{\text {st }}$ was also significant for all population pairs (Table 3 ), in agreement with the results obtained using individual based assessment such as the clustering algorithm structure that favoured the existence of three differentiated clusters subunit I sequences. ESUs considered to represent a single species are represented by grey boxes; $(B)$ ABGD method based on recursive partitions of sequences into groups using intra and inter specific divergence. ESUs considered to represent a single species are represented by white boxes

corresponding to samples from (1) Larak, (2) Khark + Shidvar, and (3) Hendurabi (Fig. 3), also visible in the DAPC (Fig. 3a, b) and Table S2.

\section{Discussion}

\section{Phylogenetic Patterns and Species Delimitation}

This study presents new evidence to support the black-lip pearl oyster $P$. margaritifera as a species complex with each taxon encompassing distributional ranges narrower than the whole complex, despite the large distribution

Table 3 Pairwise genetic differentiation $\left(F_{\text {st }}\right)$ estimated from microsatellite data using $\theta$, with values significantly departing from the null hypothesis of panmixia indicated in bold $(p<0.01)$ or by an asterisk $(p<0.05)$

\begin{tabular}{|c|c|c|c|c|}
\hline & Larak & Khark & Shidvar & Hendurabi \\
\hline Larak & & 0.124 & 0.089 & 0.135 \\
\hline Khark & & & $0.059 *$ & $0.152 *$ \\
\hline Shidvar & & & & 0.121 \\
\hline
\end{tabular}


potential expected from organisms with extended pelagic larval phases. Our molecular analyses revealed that taxa formerly identified as subspecies based on morphological criteria (e.g. P. m. zanzibarensis or P. m. mazatlanica) belong to clearly divergent ESUs, distributed in distinct bioregions. Species delimitation tests (GMYC and ABGD) add black-lip pearl oyster specimens from the Persian Gulf as an additional independent ESU (Fig. 2A, B).

Bayesian and ML analyses (Fig. 1) based on barcoding DNA showed that the insular specimens did not cluster with the remaining $P$. margaritifera but were retrieved as sister group to an ESU formerly named $P$. $m$. zanzibarensis that should be considered as $P$. zanzibarensis (specimens from Mauritius, Indian Ocean). Given that specimens from the Gulf of California also formed a monophyletic group and represent a distinct ESU from the remaining P. margaritifera from the French Polynesia and Japan (Fig. 1), the species formerly known as $P$. m. mazatlanica should be renamed as $P$. mazatlanica.

The clade formed by black-lip pearl oysters from the Persian Gulf was well supported by both BI (BPP: 100) and ML (BP: 97) analyses (Fig. 1). Both approaches (phylogenetic analyses and species delimitation tests) provided solid evidence that black-lip pearl oysters from the Persian Gulf should be considered a new Pinctada species. Furthermore, the genetic distance within this group $(0.00024 \pm 0.00022)$ was much smaller than between the group and its sister clade $(0.035 \pm 0.009)$. Accordingly, we considered the black-lip pearl oysters from the Persian Gulf a putative species hereafter called Pinctada persica.

\section{Ecological Drivers of Marine Speciation}

Like most marine bivalves, the Persian Gulf black-lip pearl oysters are suspension feeders and broadcast spawners exhibiting no particular feeding or reproductive specializations, which renders more challenging the understanding of mechanisms underlying their diversification. The Persian Gulf shoreline is mainly composed of sandy bottoms, which is not the preferred habitat for $P$. persica. Along the Iranian coasts, most of the coral reef areas that tend to be the preferred habitat for other ESUs of the P. margaritifera complex are located on Nayband bay, Nakhiloo peninsula and Chabahar (Iranian coast of the Oman Sea), where no specimens of $P$. persica were reported thus far. Intriguingly, $P$. radiata can be found in some of those continental locations (e.g., Nakhiloo, see Fig. 1 for map location).

Pinctada persica occurs in very small numbers on few islands of the Persian Gulf. Contacts among local fishermen, and more than 150 dives performed in this area between 2011 and 2012, confirmed the complete lack of record and most likely absence (or extreme scarcity) from continental locations. Regardless their long pelagic larval duration, some species within the genus Pinctada exhibit some genetic structure (e.g. P. m. cumingii from the Central Pacific archipelagos, Arnaud-Haond et al. 2003a) but none presents such a restricted distribution as $P$. persica. This is an unusual pattern in organisms with high dispersal abilities. A recent study (Lemer and Planes 2014) using microsatellite data showed, however, high levels of connectivity between populations of $P$. margaritifera from the a

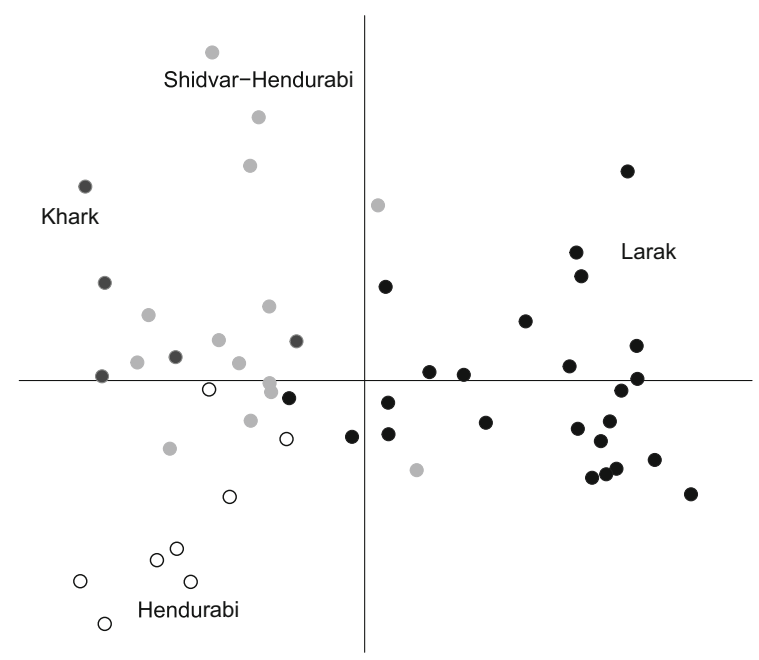

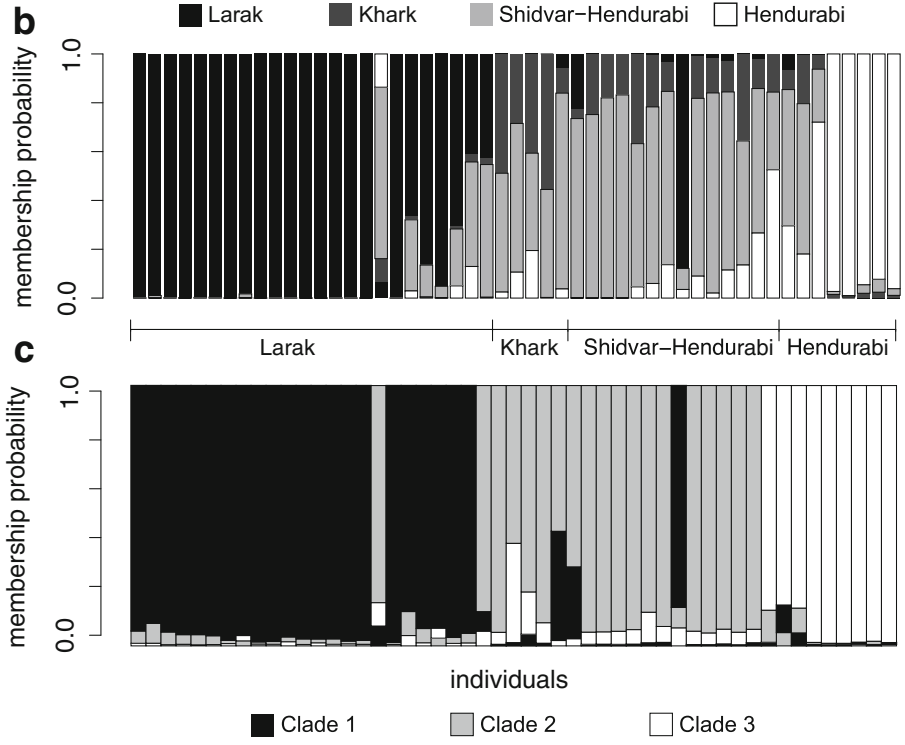

cluster probabilities, for most likely number of clusters $(\mathrm{K}=3$ ) (if an individual is assigned to multiple clusters, bars are stacked). Both b and c consist of 51 stacked bars, in which each bar is one individual and the order of the individuals is the same in both graphs
Fig. 3 Inferred population structure of the black-lip pearl oysters from the Persian Gulf based on microsatellite data. a DAPC scatterplot on individuals; b DAPC stacked bar graph of population assignment probabilities per individual (if an individual is assigned to multiple locations, bars are stacked); c STRUCTURE plot of membership 
French Polynesia despite their fragmented habitat (South Pacific oceanic islands). It is important to stress that, although $P$. margaritifera populations are restricted to oceanic islands as well as $P$. persica, the habitat of the latter is, comparatively, much more confined given the reduced size of the Persian Gulf Islands.

The pearl oysters $P$. persica and $P$. radiata from the Persian Gulf are frequently found in sympatry but some subtle differences regarding geographic distribution and preferential habitats can be identified. $P$. radiata is widely distributed along the Persian Gulf whereas $P$. persica occurs exclusively on insular locations. While $P$. persica only inhabits areas associated with strong currents, $P$. radiata can also be found in calm waters (pers. obs., Sharif Ranjbar).

\section{Eustatic Sea-Level Changes in the Persian Gulf During the Plio-Pleistocene and the Diversification of the Black-Lip Pearl Oysters}

We examined whether the relatively long branches corresponding to the divergence between $P$. persica and $P$. zanzibarensis (Fig. 2) could result from a shift (acceleration) in the diversification rate or represent instead high background extinction rates (Harvey et al. 1994). According to the relative cladogenesis statistic, we found no evidence of shifts in the diversification rates across the phylogeny and thus, the occurrence of background extinction rates seems a more plausible hypothesis.

The Persian Gulf, an exceptionally shallow sea with a maximum depth of $90 \mathrm{~m}$ (Walkden and Williams 1998), attained its present-day shape in the late Pliocene (Sohrabipour and Rabiei 2007). A recent study (Rohling et al. 2014) based on sea-level reconstructions recorded a marked cooling event during the Pleistocene at 2.73 myr followed by a major glaciation at 2.15 myr that caused a significant drop in the eustatic (global) sea level below $70 \mathrm{~m}$. According to our Bayesian estimates, P. persica shared a most recent common ancestor (MRCA) with $P$. zanzibarensis during the same period (2.29 myr; Fig. 2). The MRCA of both lineages were most likely distributed in the Indian Ocean and adjacent seas (including the Persian Gulf) during the Plio-Pleistocene. Considering the reduced depth of the Persian Gulf, a low sea level stand of this magnitude should have had a major impact on coastal organisms, such as pearl oysters.

$P$. persica is deeply divergent from its sister species, $P$. zanzibarensis from Mauritius (Fig. 1). The Plio-Pleistocene low sea levels may have caused two equally plausible scenarios in the Gulf region: (1) restriction of the geographic distribution of $P$. persica to the few available pockets of waters or (2) extinction of the ancestor of $P$. persica followed by a re-colonization by few specimens from the Indian Ocean. Considering that the Persian Gulf is an enclosed sea (communicates with the Indian Ocean uniquely by the Strait of Hormuz), the long-term isolation of populations inhabiting this area created conditions for allopatric divergence to occur. Both scenarios would produce monophyletic assemblages of specimens of the Persian Gulf and a sister relationship with black-lip pearl oysters from the adjacent Indian Ocean.

A similar pattern was found in the green alga Halimeda discoidea from the Arabian Sea, whose distribution is currently limited to only a few hundreds of $\mathrm{km}$ of the Omanian coastline. This pattern results from a founder population deeply divergent from its tropical counterparts by genetic drift (Reuter et al. 2012). We estimated the age of the crown group of $P$. persica at 510,000 years (Fig. 2), and the divergence from $P$. zanzibarensis at 2.29 [0.73-4.62] myr; Fig. 2), which suggests that $P$. persica may represent a descendant population from an ancient split. Given the confidence interval for the divergence ([0.73-4.62] myr), this estimate is compatible with the Plio-Pleistocene ice ages.

\section{From Past Diversification to Present Genetic Differentiation in the Persian Gulf}

The paucity and fragmented distribution of suitable habitats for $P$. persica, which is reflected in the observed patterns of microsatellite differentiation among laying beds distant of only a few dozen kilometers (e.g. Shidvar and Hendurabi; Table 3; Fig. 3), may represent a major driver of diversification within the species. With present data it is not possible to distinguish between the competing hypotheses of long-term isolation determined by fragmented suitable habitats or contemporary discontinuity of gene flow due to present-day anthropogenic influence. Both hypotheses may yield a mosaic of genetically differentiated beds on a reduced spatial scale. The Persian Gulf marine coastline is currently under substantial stress caused by heavy construction along shores reinforced by massive oil and gas industry (Sheppard et al. 2010). Habitat destruction is most likely one of the reasons for the absence of $P$. persica from the continental shores. The small-sized $P$. radiata (much smaller than $P$. persica) seems to adjust better to disturbed environmental conditions.

Shidvar has been subject to restoration through release of hatchery seed from Hendurabi (pers. comm. Hossein Rameshi; Persian Gulf Molluscs Research Centre, Bandar Lengeh, Iran), which is reflected in the highest value of $F_{\text {is }}$ (Table S2; Fig. 3). Similar results of high $F_{\text {is }}$ and strong clustering of pools of specimens resulting from releases of hatchery-produced larvae were reported in a study on $P$. margaritifera from the French Polynesia (Lemer and Planes 2012). Altogether, the substantial success of 
reseeding through the release of hatchery produced spat and the strong genetic signature in those restored laying beds, recalls the potential mid-term incidence of cultural practices on the integrity of wild populations (ArnaudHaond et al. 2003b, 2004). The sustainable restoration of wild laying beds requires precise and controlled hatchery practices to maintain a level of genetic diversity and composition as close as possible to the one present in laying beds surrounding the habitat being restored.

The small sample sizes of $P$. persica may have an impact on the results due to the observed heterogeneity in the distribution of the genetic diversity within location (i.e. genetic patchiness, Arnaud-Haond et al. 2008) or by reducing the power to detect a significant pattern. However, most fixation indices were significant and the individual-based analysis showed clearly delineated clusters. The homogeneity of each laying bed compared to the clear differentiation among them (Fig. 3) supports genetic differentiation among locations, combined or not with regional patchiness, rather than an artifact due to low sampling sizes.

A relationship between genetic and geographic distance can be expected when populations are at mutation-migration-drift equilibrium. Here, we clearly investigate a system that is out of equilibrium due to the destruction of coastal areas and the reseeding through hatchery spat. The recolonization of beds by the limited effective population size of the produced progenies, notably related to the effective number of breeders and variance of reproductive success (Hedgecock 1994; Lallias et al. 2010), mimics a founder effect that, through the magnified influence of drift, leads to an important reshuffling of the allelic frequencies. The disconnection between genetic and geographic distances altogether with high variance in $F_{\text {st }}$ values based on a limited number of samples is thus expected in such system, and may explain why Hendurabi and Shidvar are genetically more distant to each other than the latter is to any other population.

\section{Conclusions}

Sequence-based species delimitation tests and all phylogenetic analyses performed here retrieved the black-lip pearl oyster from the Persian Gulf, Pinctada persica, as an independent ESU belonging to the P. margaritifera complex. The atypical distribution range of $P$. persica circumscribed to islands that are closely located to the mainland and its absence from continental locations, represents an unusual pattern in organisms exhibiting a long pelagic larval phase. While its restricted range may result from the biogeographic history of isolation and divergence in a changing environment, the paucity and highly fragmented distribution of suitable habitats is likely intensified by the anthropogenic disturbance of continental habitats.

Such low abundances and extremely restricted geographic distribution together with habitat destruction and the genetic imprint left by restoration programs through hatchery-produced spat raises some concerns regarding the long-term viability of $P$. persica. The use of large and distinct pools of breeders and the increase in the density of broadcast spawners in laying beds may favour the success of restoration programs and increase the viability of this species. The genetic distinctiveness of laying beds restored with hatchery-produced oysters also reflects further ongoing changes linked to human practices. The status of $P$. persica confined to a restricted geographical area with suitable habitats poorly connected, stresses the importance of listing this unique species on international conservation priorities.

\section{Compliance with Ethical Standards}

Conflict of interest The authors declare that they have no conflict of interest.

\section{References}

Akaike, H. (1973). Information theory as an extension of the maximum likelihood principle. In B. N. P. F. Csaksi (Ed.), 2nd international symposium on information theory (pp. 267-281). Budapest: Akademiai Kiado.

Arnaud-Haond, S., Bonhomme, F., \& Blanc, F. (2003a). Large discrepancies in differentiation of allozymes, nuclear and mitochondrial DNA loci in recently founded Pacific populations of the pearl oyster Pinctada margaritifera. Journal of Evolutionary Biology, 16, 388-398.

Arnaud-Haond, S., Vonau, V., Bonhomme, F., Boudry, P., Prou, J., Seaman, T., et al. (2003b). Spat collection of the pearl oyster (Pinctada margaritifera cumingii) in French Polynesia: An evaluation of the potential impact on genetic variability of wild and farmed populations after 20 years of commercial exploitation. Aquaculture, 219, 181-192.

Arnaud-Haond, S., Vonau, V., Boudry, P., Blanc, F., Prou, J., Seaman, T., \& Goyard, E. (2004). Spatio-temporal variation in the genetic composition of wild populations of pearl oyster (Pinctada margaritifera cumingii) in French Polynesia following 10 years of juvenile translocation. Molecular Ecology, 13, 2001-2007.

Arnaud-Haond, S., Vonau, V., Rouxel, C., Bonhomme, F., Prou, J., Goyard, E., \& Boudry, P. (2008). Genetic structure at different spatial scales in the pearl oyster (Pinctada margaritifera cumingii) in French Polynesian lagoons: Beware of sampling strategy and genetic patchiness. Marine Biology, 155, 147-157.

Bassam, B. J., Anollés, G. C., \& Gresshoff, P. M. (1991). Fast and sensitive silver staining of DNA in polyacrylamide gels. Analytical Biochemistry, 196, 80-83.

Belkhir, K., Borsa, P., Chikhi, L., Raufaste, N., \& Bonhomme, F. (1996-2004). GENETIX 4.05, logiciel sous Windows TM pour la génétique des populations. Montpellier: Université de Montpellier II, Laboratoire Génome, Populations, Interactions, CNRS UMR 5000 . 
Black, W. C., \& Krafsur, E. S. (1985). A fortran program for the calculation and analysis of two-locus linkage disequilibrium coefficients. Theoretical and Applied Genetics, 70, 491-496.

Bouckaert, R., Heled, J., Kühnert, D., Vaughan, T., Wu, C.-H., Xie, D., et al. (2014). BEAST 2: A software platform for Bayesian evolutionary analysis. PLoS Computational Biology, 10(4), e1003537.

Cunha, R. L., Blanc, F., Bonhomme, F., \& Arnaud-Haond, S. (2011). Evolutionary Patterns in Pearl Oysters of the Genus Pinctada (Bivalvia: Pteriidae). Marine Biotechnology, 13, 181-192.

Doyle, J. J., \& Doyle, J. L. (1987). A rapid DNA isolation procedure for small quantities of fresh leaf tissue. Phytochemical Bulletin, $19,11-15$

Drummond, A. J. B. A., Buxton, S., Cheung, M., Cooper, A., Duran, C., Field, M., et al. (2010). Geneious v5.5. http://www.geneious. com. Last accessed March 12, 2012.

Drummond, A. J., Ho, S. Y. W., Philips, M. J., \& Rambaut, A. (2006). Relaxed phylogenetics and dating with confidence. PLoS Biology, 4(5), e88.

Drummond, A., \& Rambaut, A. (2008). Tracer V.1.5. http://beast.bio. ed.ac.uk/Tracer.

Drummond, A. J., Suchard, M. A., Xie, D., \& Rambaut, A. (2012). Bayesian phylogenetics with BEAUti and the BEAST 1.7. Molecular Biology and Evolution, 29(8), 1969-1973.

Earl, D. A. (2012). STRUCTURE HARVESTER: A website and program for visualizing STRUCTURE output and implementing the Evanno method. Conservation Genetics Resources, 4(2), 359-361.

Evanno, G., Regnaut, S., \& Goudet, J. (2005). Detecting the number of clusters of individuals using the software STRUCTURE: A simulation study. Molecular Ecology, 14(8), 2611-2620.

Folmer, O., Black, M., Hoeh, W., Lutz, R., \& Vrijenhoek, R. (1994). DNA primers for amplification of mitochondrial cytochrome $\mathrm{c}$ oxidase subunit I from diverse metazoan invertebrates. Molecular Marine Biology and Biotechnology, 3, 294-297.

Gervis, M. H., \& Sims, N. A. (1992). The biology and culture of pearl oysters (Bivalvia: Pteriidae) (Vol. 21, pp. 1-49). International Center for living aquatic resources management.

Guindon, S., \& Gascuel, O. (2003). A simple, fast and accurate algorithm to estimate large phylogenies by maximum likelihood. Systematic Biology, 52(5), 696-704.

Harvey, P. H., May, R. M., \& Nee, S. (1994). Phylogenies without fossils. Evolution, 48(3), 523-529.

Hasan, A. K. (1994). A taxonomic review of the bivalve and gastropod mollusc fauna along the Saudi intertidal zone of the Arabian Gulf. Journal of King Abdulaziz University: Marine Sciences, 7, 245-253.

Hedgecock, D. (1994). Does variance in reproductive success limit effective population size of marine organisms? In A. Beaumont (Ed.), Genetics and evolution of aquatic organisms (pp. 122-134). London: Chapman \& Hall.

Herbinger, C., Smith, C. A., \& Langy, S. (2006). Development and characterization of novel tetra-and dinucleotide microsatellite markers for the French Polynesia black-lipped pearl oyster, Pinctada margaritifera. Molecular Ecology Notes, 6(1), 107-109.

Hertlein, L. G., \& Cox, L. R. (1969). Family Pteriidae Gray, 1847 (1820). In L. R. Cox, N. D. Newell, D. W. Boyd, C. C. Branson, R. Casey, R. Chavan, et al. (Eds.), Treatise on invertebrate paleontology. Part N. Mollusca 6: Bivalvia (Vol. 1, pp. N302N306). Lawrence, KS: Geological Society of America and University of Kansas.

Hollander, J. (2008). Testing the grain-size model for the evolution of phenotypic plasticity. Evolution, 62(6), 1381-1389.

Huelsenbeck, J. P., \& Ronquist, F. R. (2001). MrBayes: Bayesian inference of phylogeny. Bioinformatics, 17, 754-755.
Huelsken, T., Keyse, J., Liggins, L., Penny, S., Treml, E. A., \& Riginos, C. (2013). A novel widespread cryptic species and phylogeographic patterns within several giant clam species (Cardiidae: Tridacna) from the Indo-Pacific Ocean. PLos ONE, 8(11), e80858. doi:10.1371/journal.pone.0080858.

Jameson, H. L. (1901). On the identity and distribution of the motherof-pearl oysters; with a revision of the sub-genus Margaritifera. Proceedings of the General Meetings for Scientific Business of the Zoological Society of London, 1, 372-394.

Jombart, T. (2008). adegenet: A R package for the multivariate analysis of genetic markers. Bioinformatics, 24, 1403-1405.

Katoh, K., \& Toh, H. (2010). Parallelization of the MAFFT multiple sequence alignment program. Bioinformatics, 26(15), 1899-1900.

Kimura, M. (1980). A simple method for estimating evolutionary rates of base substitutions through comparative studies of nucleotide sequences. Journal of Molecular Evolution, 16, 111-120.

Lallias, D., Boudry, P., Lapegue, S., King, J. W., \& Beaumont, A. R. (2010). Strategies for the retention of high genetic variability in European flat oyster (Ostrea edulis) restoration programmes. Conservation Genetics, 11(5), 1899-1910.

Lemer, S., \& Planes, S. (2012). Translocation of wild populations: Conservation implications for the genetic diversity of the blacklipped pearl oyster Pinctada margaritifera. Molecular Ecology, 21(12), 2949-2962.

Lemer, S., \& Planes, S. (2014). Effects of habitat fragmentation on the genetic structure and connectivity of the black-lipped pearl oyster Pinctada margaritifera populations in French Polynesia. Marine Biology, 161(9), 2035-2049.

Marshall Dustin, J., \& Morgan Steven, G. (2011). Ecological and evolutionary consequences of linked life-history stages in the sea. Current Biology, 21(18), R718-R725.

Mohammed, S. Z., \& Al-Khayat, J. A. (1994). A preliminary checklist of benthic mollusca on the Qatari coasts, Arabian Gulf. Qatar University Science Journal, 14(1), 201-206.

Monaghan, M. T., Wild, R., Elliot, M., Fujisawa, T., Balke, M., Inward, D. J., et al. (2009). Accelerated species inventory on Madagascar using coalescent-based models of species delineation. Systematic Biology, 58(3), 298-311.

Moore, E. J. (1983). Tertiary marine pelecypods of California and Baja California: Nuculidae through Malleidae (pp. A1-A108). Geological Survey Professional Paper 1228-A.

Nanninga, G. B., \& Berumen, M. L. (2014). The role of individual variation in marine larval dispersal. Frontiers in Marine Science, 1, 71. doi:10.3389/fmars.2014.00071.

Payo, D. A., Leliaert, F., Verbruggen, H., D'hondt, S., Calumpong, H. P., \& De Clerck, O. (2013). Extensive cryptic species diversity and fine-scale endemism in the marine red alga Portieria in the Philippines. Proceedings of the Royal Society B: Biological Sciences, 280(1753), 20122660.

Pons, J., Barraclough, T., Gomez-Zurita, J., Cardoso, A., Duran, D., Hazell, S., et al. (2006). Sequence-based species delimitation for the DNA taxonomy of undescribed insects. Systematic Biology, 55(4), 595-609.

Porebski, S., Bailey, L. G., \& Baum, R. B. (1997). Modification of a CTAB DNA extraction protocol for plants containing high polysaccharide and polyphenol components. Plant Molecular Biology Reporter, 15(1), 8-15.

Posada, D., \& Crandall, E. D. (1998). Modeltest: Testing the model of DNA substitution. Bioinformatics, 14(9), 817-818.

Pritchard, J. K., Stephens, M., \& Donnelly, P. (2000). Inference of population structure using multilocus genotype data. Genetics, 155(2), 945-959.

Puillandre, N., Lambert, A., Brouillet, S., \& Achaz, G. (2012a). ABGD, Automatic Barcode Gap Discovery for primary species delimitation. Molecular Ecology, 21(8), 1864-1877. 
Puillandre, N., Modica, M., Zhang, Y., Sirovich, L., Boisselier, M. C., Cruaud, C., et al. (2012b). Large-scale species delimitation method for hyperdiverse groups. Molecular Ecology, 21(11), 2671-2691.

R Development Core Team. (2013). $R$ : A language and environment for statistical computing. $\mathrm{R}$ Foundation for Statistical Computing.

Rambaut, A., Harvey, P. H., \& Nee, S. (1997). End-Epi: An application for reconstructing phylogenetic and population processes from molecular sequences. Computer Applications in the Biosciences, 13, 303-306.

Rambaut, A., Suchard, M. A., Xie, D., \& Drummond, A. J. (2014). Tracer version 1.6.

Rameshi, H. (2014). Annual report of Persian Gulf molluscs research Center (in Persian).

Reuter, M., Piller, W. E., \& Richoz, S. (2012). The dispersal of Halimeda in northern hemisphere mid-latitudes: Palaeobiogeographical insights. Perspectives in Plant Ecology, Evolution and Systematics, 14(4), 303-309.

Rohling, E., Foster, G., Grant, K., Marino, G., Roberts, A., Tamisiea, M., \& Williams, F. (2014). Sea-level and deep-sea-temperature variability over the past 5.3 million years. Nature, 508(7497), 477-482.
Sheppard, C., Al-Husiani, M., Al-Jamali, F., Al-Yamani, F., Baldwin, R., Bishop, J., et al. (2010). The Gulf: A young sea in decline. Marine Pollution Bulletin, 60(1), 13-38.

Sims, N. A. (1992). Pearl oyster Honiara. Solomon Islands: Pacific Islands Forum Fisheries Agency.

Sohrabipour, J., \& Rabiei, R. (2007). The checklist of green algae of the Iranian coastal lines of the Persian Gulf and Gulf of Oman. The Iranian Journal of Botany, 13(2), 146-149.

Tajima, F., \& Nei, M. (1984). Estimation of evolutionary distance between nucleotide sequences. Molecular Biology and Evolution, 1, 269-285.

Tamura, K., Peterson, D., Peterson, N., Stecher, G., Nei, M., \& Kumar, S. (2011). MEGA5: Molecular evolutionary genetics analysis using maximum likelihood, evolutionary distance, and maximum parsimony methods. Molecular Biology and Evolution, 28(10), 2731-2739.

Walkden, G., \& Williams, A. (1998). Carbonate ramps and the Pleistocene-Recent depositional systems of the Arabian Gulf. Geological Society, London, Special Publications, 149(1), 43-53.

Weir, B. S., \& Cockerham, C. C. (1984). Estimating F-statistics for the analysis of population structure. Evolution, 38, 1358-1370. 